\title{
ESTÁGIO DE VIVÊNCIA EM ENGENHARIA AGRONÔMICA: RELAÇÃO ENTRE O TEÓRICO E O PRÁTICO
}

\author{
G.BATISTA ${ }^{1}$, G.A.SANTOS ${ }^{2}$, T.B.MARINO ${ }^{3}$, S.R. GREGORIO ${ }^{4}$, G.F.VITA ${ }^{5}$ \\ Universidade Federal Rural do Rio de Janeiro ${ }^{1-5}$ \\ ORCID ID: http://orcid.org/0000-0003-0104-36891 ${ }^{1}$ \\ azebuadas@hotmail.com ${ }^{1}$
}

DOI: $10.15628 /$ holos.2020.9641

\section{RESUMO}

O objetivo desta pesquisa foi analisar as relações estabelecidas entre o aprendizado teórico e prático no estágio de vivência do Curso de Graduação em Engenharia Agronômica do Instituto Federal de Educação Ciência e Tecnologia do Pará (IFPA), Campus Conceição do Araguaia, e sua contribuição para a formação acadêmica dos alunos. Foi realizada através de uma abordagem quali-quantitativa, onde a estratégia deu-se pela interpretação de relatórios e questionários pósestágio. O universo da pesquisa constou de 40 alunos, sendo 24 avaliados por relatórios e 16 por questionários, além de cinco professores e 16 famílias de produtores rurais, também avaliados por questionários. Como resultado, $87,50 \%$ dos alunos reconheceram a contribuição do estágio para sua formação, com uma taxa de $100,00 \%$ de recomendação dessa prática para outros discentes. Os docentes também consideraram essa prática muito importante para os alunos $(100,00 \%)$, mas indicaram uma baixa contribuição do IFPA para sua execução $(60,00 \%)$. Em relação às famílias dos produtores, $93,75 \%$ reconheceram a importância do estágio, mas apenas $43,75 \%$ acreditavam plenamente no processo de aprendizado. Observou-se que o processo de estágio de vivência abre oportunidades para refletir sobre a relação entre o conhecimento teórico e prático, contribuindo para a formação de profissionais mais conscientes. Essa iniciativa também aborda as problematizações comumente associadas à prática formativa, fortalecendo a área de estágio como um campo científico.

PALAVRAS-CHAVE: Formação profissional, Práticas pedagógicas, Estágio acadêmico, Ensino-Aprendizagem.

\section{EXPERIENCE INTERNSHIP IN AGRONOMIC ENGINEERING: RELATIONSHIP BETWEEN THE THEORETICAL AND THE PRACTICAL}

\begin{abstract}
The objective of this research was to analyze the relationship established between the theoretical and practical learning concerning the experience internship of the Graduation Course in Agricultural Engineering at the Instituto Federal de Educação Ciência e Tecnologia do Pará (IFPA), Conceição do Araguaia campus, and its contribution to the students' academic formation. It was realized through a quality-quantitative approach, where the strategy was based on the interpretation of postinternship reports and questionnaires. The research universe consisted of 40 students, being 24 evaluated by reports and 16 by questionnaires, in addition to 5 teachers and 16 families of rural producers also subjected to questionnaires. As a result, $87.50 \%$ of the students recognized the internship's contribution to their
\end{abstract}

formation, with a recommendation rate of this practice for other students at $100.00 \%$. The teachers have also considered this practice very important for students $(100.00 \%)$, despite indicating a low contribution from the IFPA to its execution $(60.00 \%)$. With respect to the producers' families, $93.75 \%$ deemed the internship as very important, but only $43.75 \%$ fully believed in the learning process. It was observed that the experience internship process creates opportunities to reflect on the relationship between theoretical and practical knowledge, contributing to the formation of more conscious professionals. This initiative also addresses the issues commonly associated with training practice, strengthening the internship area as a scientific field.

KEYWORDS: Professional formation, Pedagogical practices, Academic internship, Teaching-Learning. 


\section{INTRODUÇÃO}

O estágio de vivência é um período muito importante na formação inicial e é esperado pelos estudantes dos cursos de Engenharia Agronômica com muita expectativa. Para esses, o único contato que tiveram com os fazeres profissionais, em formação, até então foi na condição de alunos, mas agora os papéis se invertem, quando se vêem prestes a se formarem e tendo que assumir a função de futuros profissionais (Freitas et al., 2011; Brito et al., 2018).

O estágio de vivência comumente adotado no Curso de Graduação em Engenharia Agronômica, do Instituto Federal de Educação Ciência e Tecnologia do Pará (IFPA), Campus Conceição do Araguaia, busca por um perfil estudantil propício a atender as demandas sociais e pelo desenvolvimento oportuno de competências e habilidades para os alunos, assegurando o contato do formando com situações, contextos e instituições que permita não só a aquisição de habilidades, mas também atitudes que o revelem como profissional.

O Projeto Pedagógico do Curso, construído em consonância com os valores educacionais difundidos pelo educador Paulo Freire (2002), assegura a sua importância enquanto agente de desenvolvimento local e regional.

Dessa forma, a implantação do curso visou alavancar um processo de desenvolvimento a partir da região em que está localizado. Para tal, sua ação deve ultrapassar os muros e ir para além da compreensão da educação profissional tecnológica, como mero instrumento de capitação de pessoas, para o trabalho determinado por um mercado que impõe seus objetivos. Para Freire (2002), ultrapassar os muros significa promover uma formação que possibilite uma visão ampla do ambiente social, reconhecendo e considerando peculiaridades de cada contexto.

O contexto socioambiental da região na qual o Campus está inserido, de maneira particular, e do Pará, de modo geral, é composto por uma diversidade de configurações territoriais (Little, 2003), tais como: assentados, ribeirinhos, quilombolas, indígenas, pescadores, extrativistas, entre outros, que se inscrevem na cartografia do cenário amazônico.

Esta pesquisa dispõe a interpretar o estágio de vivência, parte obrigatória do curso em questão, como ferramenta de capacitação profissional a serviço da região, na atualidade, empenhada em resolver e abrigar positivamente os problemas de sua população. Parte ainda do propósito dos pesquisadores em entender os problemas vivenciados pelos alunos durante o estágio, e da percepção de sua importância perante a comunidade e professores.

Existe um interesse em interpretar a situação em estudo sob o olhar dos próprios participantes. O foco de interesse é a perspectiva dos informantes da pesquisa, a flexibilidade na conduta do estudo. Interessa conhecer o processo, não só o resultado. Além disso, assimilar a situação em análise, algo referente ao comportamento das pessoas na formação da experiência. 
Entendendo a importância do estágio nos processos de formação, a presente pesquisa teve como objetivo analisar as relações entre o teórico e o prático, no estágio de vivência do Curso de Graduação em Engenharia Agronômica, do Instituto Federal de Educação Ciência e Tecnologia do Pará (IFPA), Campus Conceição do Araguaia, e sua contribuição para a formação acadêmica dos alunos. Ademais, identificar se os discentes participantes consideram que existe uma correlação entre os conhecimentos teóricos e práticos, vivenciados durante o estágio de vivência; verificar se as famílias participantes consideram que o estágio de vivência pode contribuir para a formação profissional do acadêmico e quais as vantagens e desvantagens em receber os alunos estagiários; e, investigar a eficiência do estágio de vivência, sob a ótica dos professores, dos alunos e da comunidade participante, se os resultados dessa prática estão sendo eficientes na formação acadêmica, como previsto no Projeto Pedagógico do Curso.

Parte-se da premissa de que é a partir da integração entre teoria e prática, da interação entre os estudantes e a realidade dos agricultores, e da sensibilização do estudante, que surgem os resultados, mesmo que muitos sejam de longo prazo, onde se espera que o estudante passe a atuar em sua própria realidade, transformando-a.

O estágio de vivência constitui-se como uma das etapas fundamentais na vida do acadêmico e apresenta algumas vantagens para aqueles que vivenciam o ambiente de trabalho, familiarizando-se com a rotina e as possibilidades de inserção no mercado de trabalho. Pode ser um facilitador da união entre teoria e prática, atenuand o o impacto da passagem da vida estudantil para a vida profissional, contribuindo para reduzir a situação de insegurança, e buscando com a prática acentuar a confiança em suas potencialidades (Cardoso et al., 2009; Coutinho et al., 2013).

\section{MATERIAL E MÉTODOS}

A pesquisa foi desenvolvida no Programa de Pós-Graduação em Educação Agrícola, Instituto de Agronomia, Universidade Federal Rural do Rio de Janeiro, município de Seropédica, estado do Rio de Janeiro, no período de 2015 a 2017.

Trata-se de uma pesquisa com abordagem quantitativa, como meio de alcançar os objetivos propostos pelo estudo, sem abandonar a versão qualitativa, como convém às ciências sociais; ainda optou-se por uma análise descritiva, cuja estratégia deu-se pelo estudo de caso (Yin, 2014). Para tal, foram utilizados para coleta de dados: análise documental, interpretação dos relatórios pós-estágio e questionários.

A pesquisa teve como locus de experimentação o Instituto Federal de Educação, Ciência e Tecnologia do Pará (IFPA), Campus Conceição do Araguaia, com coordenadas de 08 $15^{\prime} 6.58^{\prime \prime} \mathrm{S}$ e $49^{\circ} 15^{\prime} 32.84^{\prime \prime}$ W de Greenwich, e extensão total de 3,74 ha aproximadamente, e propriedades rurais da Colônia Joncon, com coordenadas de 07050'41.73" S e 49¹7'27.20" W de Greenwich, e extensão total de 56,91 ha aproximadamente, ambas as localidades pertencentes ao município de Conceição do Araguaia, estado do Pará (Google Earth, 2019). 
O universo da pesquisa representou uma população pré-definida por características necessárias ao estudo em questão, portanto, 40 alunos do terceiro, quarto e quinto períodos do Curso de Graduação em Engenharia Agronômica da Instituição, sendo 24 avaliados por relatórios pós-estágio e 16 por questionários, cinco professores dos respectivos cursos e 16 famílias rurais residentes na Colônia Joncon, que acolheram os alunos, ambos avaliados por questionários.

A pesquisa documental foi fomentada com o objetivo de levantar informações sobre a competência institucional, relativas ao estágio de vivência do IFPA, Campus Conceição do Araguaia, baseando-se nos depoimentos de alunos, professores e famílias acolhedoras dos estagiários do Curso de Graduação em Engenharia Agronômica da referida Instituição, em comparação ao proposto pelo Projeto Pedagógico do Curso (PPC, 2011).

Os relatórios foram examinados de forma a compreender como o aluno percebeu o estágio, sendo utilizado como metodologia para tal fim, uma ferramenta denominada TagCrowd $^{\circledR}$ (Tagcrowd, 2019), cuja técnica se propõe a produzir uma nuvem de palavras que mostra de forma clara as principais informações que um conteúdo deseja passar. Nesse momento, foram identificadas as passagens mais relevantes nos relatórios, e essas foram interpretadas de acordo com a experiência do autor.

Os questionários foram elaborados por perguntas com fins didáticos para enriquecimento da pesquisa, e foram assim organizados: para os alunos, com quatro perguntas abertas, sete fechadas e seis em escala Likert de cinco pontos, variando de "discordo totalmente" a "concordo totalmente" (Likert, 1932; Alexandre \& Ferreira, 2001); para os professores, com cinco perguntas fechadas, passíveis de justificativa, e uma aberta; e, para as famílias dos produtores, com 12 perguntas fechadas. Os questionários foram distribuídos por e-mail aos alunos e professores, os quais tiveram prazo de 15 dias para devolução. Com relação às famílias dos produtores, os questionários foram aplicados pessoalmente pelo pesquisador.

A caracterização dos grupos participantes ficou assim composta:

Grupo 1) 24 alunos na composição dos relatórios de estágio e 16 alunos respondentes do questionário, todos participantes do estágio de vivência. Quanto ao roteiro do questionário, os indicadores foram: idade, sexo, conhecimento da regulamentação de estágio da Instituição; conhecimento sobre o estágio de vivência da Instituição; conhecimento dos objetivos do estágio de vivência; em ordem de importância listagem dos objetivos do estágio de vivência; relações entre o conteúdo abordado em aula com futuras atividades profissionais observadas durante o estágio de vivência; em ordem de importância listagem do conteúdo abordado em aula com futuras atividades profissionais observadas durante o estágio de vivência; espaços/equipamentos disponíveis do Instituto adequados para a realização das atividades relacionadas ao curso; tipos de espaços/equipamentos mais deficientes; estrutura física da propriedade adequada para as atividades do estágio; o que mais contribuiu para o desenvolvimento das atividades do estágio; recomendação para o estágio de vivência; principal experiência que o estágio de vivência 
oportunizou e que o IFPA não ofereceu; a quem direcionou perguntas sobre as atividades que estavam executando durante o estágio de vivência; considera justo e adequado o sistema de avaliação proposto no estágio de vivência; e, como considera seu estágio.

Grupo 2) cinco docentes que supervisionaram os estudantes durante o estágio de vivência. O roteiro do questionário foi definido pelos indicadores: importância do estágio de vivência para o curso de Engenharia Agronômica; valorização do curso sobre o olhar docente; dificuldades na estruturação do estágio de vivência; aplicação do estágio de vivência de forma correta; participação de todos os professores no acompanhamento do estágio de vivência; e, a gestão geral do IFPA contribui para uma boa execução do estágio de vivência.

Grupo 3) 16 famílias de produtores que acolheram os alunos. Quanto ao roteiro do questionário, os indicadores foram: tamanho da família; característica da família; grau de escolaridade; quem da família teve mais contato com o estagiário; tipo de contato com o estagiário; permanência do estagiário na propriedade durante o período do estágio; atividades desenvolvidas pelos alunos estavam de acordo com as instruções dadas pela família; o aluno trouxe incômodo para a família; o estágio de vivência é importante para os alunos; a presença dos alunos foi benéfica em suas propriedades; comentário dos alunos a respeito das aulas teóricas em relação às práticas desenvolvidas na propriedade; e, credibilidade da família no aprendizado adquirido pelos alunos durante o estágio.

Todas as informações dos participantes respondentes do questionário foram utilizadas apenas para esta pesquisa, sendo o sigilo assegurado, e o consentimento fornecido a partir da assinatura do Termo de Consentimento Livre e Esclarecido (TCLE), conforme estabelecido na Resolução n. ${ }^{\circ}$ 466/2012 do Conselho Nacional de Saúde (Brasil, 2013).

\section{RESULTADOS E DISCUSSÃO}

Inicialmente, referente ao Grupo 1, onde 16 alunos responderam ao questionário, mais precisamente sobre os indicadores idade e sexo, verificou-se que os participantes possuíam idades entre 18 a 40 anos, sendo 18 a 25 a faixa etária mais presente (50,00\%). Quanto ao sexo, 50,00\% foram do sexo masculino e $50,00 \%$ do sexo feminino (Tabela 1 ).

No IFPA, Campus Conceição do Araguaia, o estágio é obrigatório, assim a pesquisa mostrou que $81,25 \%$ dos alunos entrevistados, conheciam a regulamentação de estágio da escola, avaliação obtida na escala de Likert, acima de 3, onde 1, conhecia pouco e 5 conhecia muito. Já quanto ao indicador conhecimento sobre o estágio de vivência, 62,50\% declararam conhecê-lo, sendo esse conhecimento adquirido através de leituras sobre o mesmo (Tabela 1).

Apesar de que, dentre os alunos que responderam à pesquisa, a média de conhecimento sobre o estágio de vivência ser considerada boa, deve-se refletir se a escola é igual para todos, 
pois, desde a fase inicial da escola até as graduações o ensino deve se preocupar em ser igualitário para todos respeitando a diversidade de seu público.

Quando se adota mudanças substanciais na planificação e na construção de didáticas de educação comuns à diversidade estão asseguradas metodologias interativas,

[...] que, desenvolvem a pessoa por inteiro e em que a dignidade do aluno está sempre preservada e respeitada. Esses métodos devem acentuar o direito de todos à livre expressão de suas ideias e sentimentos e as propostas de trabalho pedagógico são marcadamente democráticas, mudando o papel desempenhado por alunos e professores e as relações estabelecidas entre eles, no processo de ensino e de aprendizagem. As escolas de qualidade liberam o aprendiz da tutela do adulto e, no plano intelectual e social, a autonomia se opõe à heteronímia; a livre investigação nega o dogmatismo e a instrução não preside os atos pedagógicos, pois o que vigora é o que cada aluno é capaz de fazer, de dizer, de compreender, em um dado momento de sua trajetória escolar (Mantoan, 2004, p. 1).

Verificou-se no questionário, com respeito ao indicador conhecimento dos objetivos do estágio de vivência pelos alunos, que 50,00\% declararam possuidores de um nível ótimo de conhecimento (Tabela 1); e nesse item, além da demonstração estatística, foi pedido em expressões curtas ou palavras, seu entendimento em ordem de importância desses objetivos, os quais foram assim estabelecidos:

[...] Realidade do campo; área de carência; dificuldades; novos conhecimentos; acompanhar, vivenciar e compartilhar ideias e técnicas, aprendendo com o produtor, sem interferir no cotidiano do mesmo; é a imersão da agricultura familiar, devemos convier com os agricultores para sabermos como é o manejo de cada propriedade e como a família vive; vivência, prática e preparação do aluno; conhecer a realidade; discutir o conhecimento empírico (Verbalizações indiscriminadas dos alunos).

Tabela 1: Indicadores disponibilizados em questionário aos 16 alunos participantes da pesquisa, como parte da investigação sobre as relações estabelecidas entre a teoria e a prática no estágio de vivência, e sua contribuição para a formação acadêmica dos alunos.

\begin{tabular}{|c|c|c|}
\hline Indicadores* & Número & Percentual (\%) \\
\hline Idade & & \\
\hline$>17$ & 0 & 0,00 \\
\hline 18 a 25 & 8 & 50,00 \\
\hline $26-40$ & 6 & 37,50 \\
\hline$<41$ & 2 & 12,50 \\
\hline Sexo & & \\
\hline Masculino & 8 & 50,00 \\
\hline Feminino & 8 & 50,00 \\
\hline Conhecimento da regulamentação de estágio da Ins & & \\
\hline Sim & 13 & 81,25 \\
\hline Não & 3 & 18,75 \\
\hline Como adquiriu conhecimento sobre o estágio de vil & & \\
\hline Por ler a respeito & 10 & 62,50 \\
\hline Por ouvir falar a respeito & 4 & 25,00 \\
\hline Outro & 2 & 12,50 \\
\hline Conhecimento dos objetivos do estágio de vivência & & \\
\hline
\end{tabular}

HOLOS, Ano 36, v.4, e9641, 2020 


\begin{tabular}{|c|c|c|}
\hline $\begin{array}{l}\text { Ótimo } \\
\text { Insatisfatório }\end{array}$ & $\begin{array}{l}8 \\
8\end{array}$ & $\begin{array}{l}50,00 \\
50,00\end{array}$ \\
\hline $\begin{array}{l}\text { Espaços/equipamentos disponíveis do Instituto adequados para a realização das } \\
\text { atividades relacionadas ao curso } \\
\text { Plenamente adequados } \\
\text { Muito adequados } \\
\text { Bem adequados } \\
\text { Pouco adequados } \\
\text { Inadequados }\end{array}$ & $\begin{array}{l}0 \\
0 \\
4 \\
4 \\
8\end{array}$ & $\begin{array}{l}0,00 \\
0,00 \\
25,00 \\
25,00 \\
50,00\end{array}$ \\
\hline $\begin{array}{l}\text { Tipos de espaços/equipamentos mais deficientes } \\
\text { Laboratório } \\
\text { Campo } \\
\text { Outros }\end{array}$ & $\begin{array}{l}9 \\
7 \\
0\end{array}$ & $\begin{array}{c}56,25 \\
43,75 \\
0,00\end{array}$ \\
\hline $\begin{array}{l}\text { Estrutura física da propriedade adequada para as atividades do estágio } \\
\text { Ruim } \\
\text { Boa } \\
\text { Regular }\end{array}$ & $\begin{array}{c}1 \\
11 \\
4\end{array}$ & $\begin{array}{l}6,25 \\
69,00 \\
25,00\end{array}$ \\
\hline $\begin{array}{l}\text { Você recomendaria o estágio de vivência } \\
\text { Sim } \\
\text { Não }\end{array}$ & $\begin{array}{c}16 \\
0\end{array}$ & $\begin{array}{c}100,00 \\
0,00\end{array}$ \\
\hline $\begin{array}{l}\text { A quem direcionou perguntas sobre as atividades que estava executando durante o } \\
\text { estágio de vivência** } \\
\text { Produtores } \\
\text { Professores } \\
\text { Colegas }\end{array}$ & $\begin{array}{c}15 \\
8 \\
5\end{array}$ & $\begin{array}{l}93,75 \\
50,00 \\
31,25\end{array}$ \\
\hline $\begin{array}{l}\text { Considera justo e adequado o sistema de avaliação proposto no estágio de vivência } \\
\text { Concordo plenamente } \\
\text { Discordo em parte } \\
\text { Discordo plenamente }\end{array}$ & $\begin{array}{c}6 \\
10 \\
0\end{array}$ & $\begin{array}{c}37,50 \\
62,50 \\
0,00\end{array}$ \\
\hline $\begin{array}{l}\text { Como considera seu estágio } \\
\text { Excelente } \\
\text { Ótimo } \\
\text { Bom } \\
\text { Ruim } \\
\text { Péssimo }\end{array}$ & $\begin{array}{l}8 \\
6 \\
2 \\
0 \\
0\end{array}$ & $\begin{array}{c}50,00 \\
37,50 \\
12,50 \\
0,00 \\
0,00\end{array}$ \\
\hline
\end{tabular}

* Os indicadores não presentes na tabela encontram-se no texto em forma de relatos.

** Valores calculados encima de múltiplas citações.

Com relação ao indicador relações entre o conteúdo abordado em aula com futuras atividades profissionais, numa abordagem referente às atividades realizadas durante o estágio de vivência, as observações não apresentaram grandes novidades, uma vez que todas as expressões e palavras obtidas através do próximo indicador: listagem em ordem de importância do conteúdo abordado em aula com futuras atividades profissionais, observadas no estágio de vivência, faziam parte da teoria e das disciplinas do curso de Agronomia.

[...] adubação; calagem; fisiologia; manejo e conservação do solo; uso de agrotóxico; planejamento, plantio; extensão rural; agro ecologia; administração rural, grandes culturas fitotecnia; fitopatologia e fertilidade do solo; controle fitossanitário na cultura do abacaxi; manejo e produção animal; irrigação (Verbalizações indiscriminadas dos alunos).

No que se refere ao indicador espaços/equipamentos disponíveis no Instituto, adequados para a realização das atividades relacionadas ao curso, numa escala de 1 a 5 , onde 1 significava 
inadequados e 5 plenamente adequados, verificou-se 50,00\% de respondentes considerando-os inadequados quanto à funcionalidade, por falta de reagentes e vidrarias, manutenção constante dos equipamentos e aparelhos usados obsoletos. O laboratório foi apontado entre os pesquisados como o espaço mais deficiente $(56,25 \%)$ (Tabela 1$)$.

Diante das avaliações sobre a aplicação e prática, no que se refere ao ambiente dentro da escola desponta-se com uma situação de atenção, pois o laboratório e o campo são os instrumentos essenciais para os estudantes de agronomia.

De acordo com Lopes et al. (2013), a escola, representada por seu corpo discente, deve propor, sempre, a representação teórica na prática, pois se isso acontecesse formar-se-iam grandes profissionais. Para tal, seria aprofundamento da compreensão de mundo, que é função e destino do laboratório, assim, cria-se segurança no aprendizado quanto à capacidade de interpretação, as possibilidades de raciocínio e imaginação. O campo segue os mesmos parâmetros e ambos deveriam ser guiados por metodologias fundamentadas e aplicadas.

A educação é um processo do próprio educando, mediante o qual são dadas à luz as ideias que fecundam sua alma. A educação consiste na atividade que cada homem desenvolve para conquistar as ideias e viver de acordo com elas. O conhecimento não vem de fora para o homem; é o esforço da alma para apoderar-se da verdade (Piletti, 1997, p. 65).

O conhecimento científico adquirido na escola tem uma contemplação que se inicia na teoria, e vai do laboratório para a prática, parâmetro comum no IFPA. $\mathrm{O}$ uso do laboratório didático no ambiente educacional, no caso da instituição que se propõe a formar agrônomos, tem dimensões gigantescas e se torna de extrema valia aos professores, que antes de impor através do estágio a prática, utilizam as atividades experimentais em suas aulas.

No Brasil, é grande o número de escolas com deficiências e carências de materiais de apoio didático, como se percebe no cotidiano, e assim, a assimilação dos conhecimentos por falta de atividades práticas, prejudica a construção dos saberes pelo educando. Há também o agravante que é a pouca importância, por vezes, dada pelos docentes, e à rara realização dessas atividades, na prática pedagógica. Como resultado ter-se-á a falta de clareza muitas vezes demonstrada pelos profissionais na prática, refletindo a carência do uso do laboratório no processo ensinoaprendizagem (Cruz, 2007; Monteiro \& Silva, 2015; Nicola \& Paniz, 2016).

O laboratório didático ajuda na interdisciplinaridade e na transdisciplinaridade, já que permite desenvolver vários campos, testar e comprovar diversos conceitos, favorecendo a capacidade de abstração do aluno. Além disso, auxilia na resolução de situações-problema do cotidiano, permite a construção de conhecimentos e a reflexão sobre diversos aspectos, levando-o a fazer interrelações. Isso o capacita a desenvolveras competências, as atitudes e os valores que proporcionam maior conhecimento e destaque no cenário sociocultural. Assim, a necessidade de inserir novas tecnologias, mostrar a importância da alfabetização científica e tecnológica no processo de formação dos indivíduos, destacar a associação entre as diferentes teorias e o ensino experimental tornam tão fundamental o uso do laboratório nas escolas, na era moderna (Cruz, 2007, p. 24). 
Fica evidente, diante do parecer teórico e da pesquisa, que há algo a ser resolvido no que se refere à estruturação de ferramentas para melhor associação da teoria à prática, dando ênfase a carência dos laboratórios e experiências de campo, que são os mais críticos.

Quanto ao indicador estrutura física da propriedade sendo adequada para as atividades do estágio, 69,00\% dos alunos mencionaram como boa (Tabela 1). Além da estrutura em si, os alunos citaram, conforme pedido, em expressões e palavras o que foi visto e o que realmente contribuiu para o desenvolvimento das atividades do estágio de vivência.

[...] Poço artesiano; mecanização; [...] por ser uma propriedade de agricultores diversificados pude participar de diversos segmentos de produção, como produção animal e vegetal; [...] localização da propriedade; transporte para ir em locais de trabalho; [...] o mês, pois é um período chuvoso na região ótimo para práticas agrícolas; [...] diversidades de plantio na propriedade; o meio desenvolvido para pesca na região; irrigação e equipamentos de pulverização (Verbalizações indiscriminadas dos alunos).

É notável que o estágio de vivência ofereça a oportunidade de o agrônomo conhecer bem mais que solos, produção animal, químicas e preparos, pois nesse estágio passa a ter um contato real com o cotidiano da produção rural e pode percebê-lo como qualquer empresa, pois necessita de estratégia e dedicação. Assim, a pesquisa mostrou que 100,00\% dos alunos pesquisados, recomendariam o estágio de vivência para os futuros estudantes de agronomia (Tabela 1).

Questionou-se como avaliação em caráter pessoal e da Instituição, qual a principal experiência que o estágio de vivência proporcionou e que o Instituto não havia oferecido ao aluno até a fase do estágio. Foram verbalizadas as seguintes palavras e expressões:

[..] tudo; dia a dia no campo; conviver com os agricultores; [...] experiências práticas, convivência no dia a dia do produtor foi essencial, o que não podemos ver em sala de aula aprendemos como conhecimento empírico; [...] prática a campo; o cotidiano dos produtores; [...] atividades práticas como despolpa de frutas, ou seja no IFPA a falta de aula prática prejudica os alunos em relação a adquirir conhecimentos; [...] a relação do profissional e o homem do campo; 15 dias de pura prática; vivenciar o dia-a-dia como se fosse o meu futuro trabalho; contato com as dificuldade sofridas pelos produtores cotidianamente (Verbalizações indiscriminadas dos alunos).

Durante a investigação citada, pôde-se evidenciar que a prática no cotidiano foi a maior revelação percebida pelos relatos dos alunos, o que leva a conclusão de que o estágio de vivência é momento extremamente válido na formação agronômica, pois permite ao aluno sentir o fazer profissional e espera-se com isto que este desenvolva a noção de educação continuada.

O contato dos estagiários com os produtores demonstrou que os alunos quiseram aprender. Afirma-se assim, porque quando foram questionados se fizeram e a quem fizeram perguntas durante a execução de atividades no estágio, todos afirmaram positivamente, sendo que $93,75 \%$ incluíram em seus questionamentos os produtores. $31,25 \%$ dirigiram-se aos colegas (Tabela 1), acredita-se que com a finalidade de comparar seu aprendizado, com seus iguais. 
O sistema de avaliação proposto pelo estágio de vivência do IFPA dá-se pela composição de relatórios, avaliações das famílias que os recebem e frequência. Assim, os alunos foram questionados se consideravam justo e adequado o sistema de avaliação proposto. Nesse indicador os resultados demonstraram grande parte dos alunos afirmando uma discordância parcial $(62,50 \%)$ (Tabela 1$)$.

Os alunos pesquisados numa escala de 1 (péssimo) a 5 (excelente) ainda avaliaram o indicador como considera seu estágio em ótimo e excelente, $37,50 \%$ e 50,00\%, respectivamente, num total de $87,50 \%$ de aceitação (Tabela 1 ). Para tal procedimento também inseriu-se opiniões escritas na forma de palavras e/ou expressões que apontassem os pontos altos do estágio:

[...] tudo; recepção do produtor e seu conhecimento; muito aprendizado, simplicidade e determinação; [...] oportunidade que nos foi dada através do reconhecimento das propriedades rurais de nossa região, bem como os ensinamentos adquiridos diretamente com o produtor; [...] interação com o meio de vida do homem do campo; bom acompanhamento dos professores, poderia melhorar mais; [...] absorvi conhecimento necessário para condução de lavouras de milho e abacaxi; nota 10 em tudo que vivenciei (Verbalizações indiscriminadas dos alunos).

As sugestões de melhorias advindas dos alunos estagiários pesquisados foram:

[...] nada; desenvolver metas para os alunos, dentro da realidade de cada propriedade; [...] 15 dias de confinamento na minha opinião é desnecessário, acredito que uma semana é tempo suficiente para o aluno entender bom o funcionamento da propriedade e as práticas de cada produtor. Assim, não altera em nada a prática dos discentes, e muito menos interfere na privacidade dos produtores; a estradas de acesso às propriedades são ruins; nada; [...] a forma com que a organização do estágio se programa para distribuir os alunos mais horas de estágios em diferentes propriedades nos locais de estágio e em diferentes propriedades; o aluno passar por mais propriedade para conhecer outras atividades; possuir mais tecnologias nas propriedades; nada; mais planejamento; aumentar para um mês; ter mais tempo, práticas; mais visitas por parte dos supervisores da instituição (Verbalizações indiscriminadas dos alunos).

Portanto, os alunos da pesquisa demonstraram alegrias, decepções e esperanças na fase de estágio de vivência nos questionários respondidos. Apontaram pontos fracos e fortes, o que certamente, permitirá melhorias ao Curso de Graduação em Engenharia Agronômica do IFPA, Campus Conceição do Araguaia, no que se refere ao estágio de vivência.

Outro momento importante nesse grupo foi a análise dos relatórios, cuja confecção foi realizada por 24 estudantes, que relataram sua rotina no estágio de vivência, descrevendo as atividades que exerceram e os aprendizados obtidos nas propriedades estagiadas. Conforme explicitado, a metodologia disposta foi através de nuvens diagnósticas, que traduziram suas informações.

Os alunos demonstraram suas preocupações para que a região em estudo evolua positivamente, melhorando a qualidade de vida dos assentados, através dos trabalhos agropecuários, e entenderam que sua inserção profissional é um importante passo para que isto 
aconteça na íntegra. Após o estágio, perceberam que o conhecimento empírico não deve ser ignorado, e sim aprimorado, conforme expressões abaixo:

[...] região Araguaia área grande número projetos assentamentos necessita profissionais perfil curso vem preparando nosso conhecimento adquirido parte teórica vida acadêmica contribuir produtor tanto quanto conhecimento prático empírico mesmo possui, contribuir formação profissionais perfil desejado mercado trabalho [...] (Aluno estagiário1).

A teoria do curso foi reconhecida na prática, como se vê no trecho abaixo e o estágio demonstrou o cuidado com o meio ambiente, certificando que houve interação da teoria com a prática.

[...] nesse processo pequenas propriedades onde foco agricultura familiar papel fundamental situação agricultura crescente demanda mundial alimento alta qualidade baixo custo forma agricultura vem sendo discutida valorizada desempenham papel importante redução produtos químicos produção possibilita aumento escala produção alteração quadro mão-obra rapidez processo realização diferentes trabalhos [...] (Aluno estagiário 2).

A profissão de agrônomo sugere que não seja a mais passiva, pois o perfil do homem do campo, com seus descuidos com a saúde e conhecimentos empíricos são construídos culturalmente. Por isso, o estágio de vivência mostra ao futuro profissional "as terras de quem ele pisa", e é claro, ao abordar uma propriedade, o agrônomo deve ter uma estratégia para aceitação das mudanças. Afirmações demonstradas nas expressões a seguir:

[...] estágio proporcionou visão ampla formas produzir pequenos produtores trabalham conhecimentos adquiridos vida, pensando produzir qualidade, levar conta própria saúde difícil aceitação mudança aprimoramento conceitos. Sendo esses obstáculos futuros engenheiros agrônomos intuito transformar realidade base conhecimentos adquiridos dentro sala aula [...] (Aluno estagiário 4).

Conforme a análise de dois trechos dos relatórios, o estágio de vivência proporcionou a convivência com a produção agropecuária, o que é de suma importância para os formandos.

[...] relatos mencionados afirmar estágio vivência suma importância tendo papel fundamental acréscimo aprendizado durante vida acadêmica estreitando relação técnico produtor mão dupla troca informações ambas as partes [...] (Aluno estagiário 10).

[...] produção abacaxi precisa acompanhamento técnico análise solo espaçamento plantas quantas plantas hectares tratos culturais combate pragas doenças investir produção galinhas ovos carne fazer aviário ofertar ração balanceada bom rendimento ganho familiar [...] (Aluno estagiário 16).

Os depoimentos ainda responderam que o estágio proporcionou aos alunos a vivência da profissão, com suas belezas e dificuldades, sendo nesse momento onde irão encontrar o que não é possível descrever em livros, e onde a descrição do ensino/aprendizagem proporcionado pelos 
professores não consegue atingir, pois ali se trata do real. Momentos únicos, com percepções individuais diferentes.

[...] Diante inúmeras experiências vivenciadas adquiridas estágio concluiu-se modalidade útil benéfica fizemos tínhamos pouco nenhum conhecimento técnicas hábitos produtores agrícolas assim acabamos ampliar nossos horizontes sobre agricultura familiar no Município [...] (Aluno estagiário 21).

Começando aqui os dados recolhidos sobre a aplicação do questionário ao Grupo 2, cinco docentes que supervisionaram os estudantes durante o estágio de vivência, a pesquisa investigou, primeiramente, o nível de importância percebida pelo grupo sobre o estágio de vivência para o Curso de Graduação em Engenharia Agronômica da Instituição em estudo, e 100,00\% dos entrevistados concordaram que este é importante para os alunos (Tabela 2).

Tabela 2: Indicadores disponibilizados em questionário aos cinco docentes participantes da pesquisa, como parte da investigação sobre as relações estabelecidas entre a teoria e a prática no estágio de vivência, e sua contribuição para a formação acadêmica dos alunos.

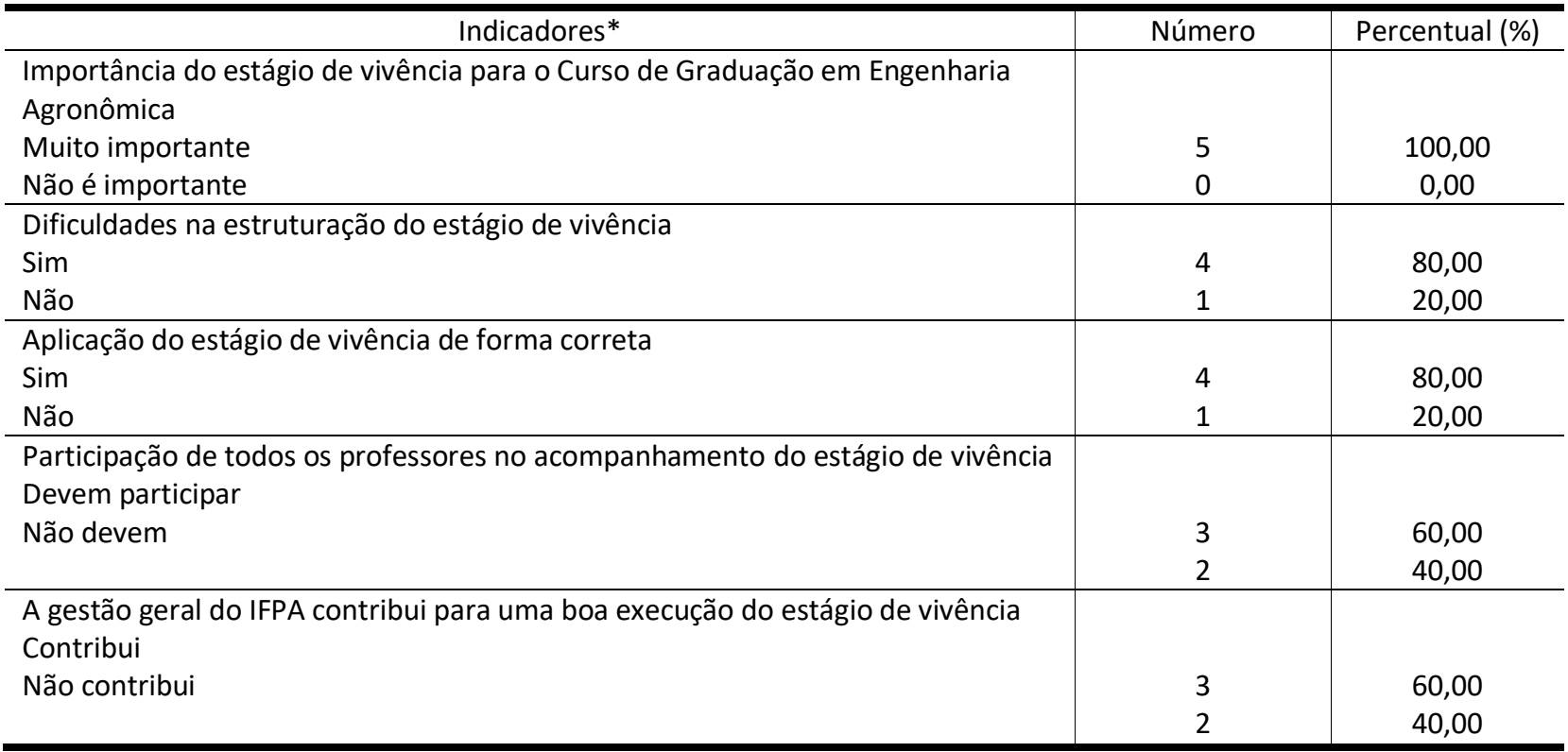

* Os indicadores não presentes na tabela encontram-se no texto em forma de relatos.

Na justificativa da resposta foram declaradas as seguintes observações:

Docente 1 (DO1): É fundamental para ampliar e enriquecer os conhecimentos dos alunos, pois através do mesmo é possível proporcionar aos discentes um pouco da realidade do campo como também oportunizar para que os mesmos possam aplicar os conhecimentos adquiridos em sala.

O estágio de Vivência surgiu como uma iniciativa dos estudantes do curso de agronomia, ainda na década de 80 , que consideravam insuficientes as experiências ofertadas pelo curso para formação de profissionais capazes de compreender a diversidade da agricultura brasileira, em especial a agricultura familiar/camponesa. A iniciativa hoje incorporada formalmente por muitos cursos mostra-se muito importante para a formação de Engenheiros Agrônomos pela IFPA, que ainda oferece um curso carregado de conteúdos que priorizam o conhecimento profundo de resultados

HOLOS, Ano 36, v.4, e9641, 2020 
de pesquisas nas ciências naturais e exatas, estimulando a formação de um tipo de profissional pouco envolvido com as pessoas e o ambiente que lhe cercam, assim como sem uma formação consistente que permita analisar cientificamente as relações sociais em ambiente rural. $O$ estágio de vivência oferece uma pequena oportunidade aos estudantes conhecerem as particularidades da agricultura praticada no município, como vivem os agricultores e suas famílias, o que fazem além da agricultura, suas dificuldades, suas expectativas, suas frustrações e os desafios daqueles que desejam manter no campo. É uma aplicação extremamente prática do conhecimento teórico.

O docente demonstrou que o estágio de vivência é tido como uma rica experiência, porém, precisa ser repensado ou entendido pelos seus superiores. Concentram suas críticas na priorização de um curso voltado para a região, mas o fato de o curso ser feito numa determinada região, não pode desvincular de sua proposta educadora que resguarda uma educação igualitária, que possa ser exercida em qualquer parte do planeta. Por outro lado, a proposta de intensificação da vivência agrônoma é válida, pois a diversidade cultural do Brasil é tão grande, que se pode afirmar como desconhecida, então o que mais aproxima de um aprendizado completo é o aprendizado humanístico que permita saber por conhecer.

Os engenheiros agrônomos são capazes de planejar e dirigir serviços de engenharia rural, desde máquinas e implementos agrícolas, irrigação e drenagem, até construções rurais, geodésica, topografia, sensoriamento remoto e geoprocessamento; desenvolver métodos e práticas agrícolas visando explorar de modo sustentável a produção vegetal; montar programas para o manejo e controle de doenças, pragas e plantas daninhas; criar programas referentes à ciência do solo, nas áreas de gênese, morfologia, classificação, fertilidade, biologia, microbiologia, uso, manejo e conservação; implantar a produção e manejo de espécies florestais nativas e exóticas e viveiros florestais; desenvolver ações de caráter socioeconômico para promover a organização e o bem estar da população; organizar atividades de gestão ambiental; e resgatar o etnoconhecimento, integrando o saber normal e o acadêmico (Paschoal, 2017, s/p).

Observa-se que a profissão de Engenheiro Agrônomo é extensa e a variedade de fatos a serem aprendidos abrange várias disciplinas, por isso a formação agronômica tem que ser concluída em sua extensão.

As demais justificativas ao item em estudo estão em comum acordo com o docente 1 e em suma vêem a oportunidade de unir a teoria à prática durante o estágio de vivência.

O Curso de Graduação em Engenharia Agronômica do IFPA, Campus Conceição do Araguaia, foi avaliado quanto a sua valorização, sob o olhar dos professores e obteve-se as seguintes respostas, de forma verbalizada e comentada:

D01: Creio que sim.

DO2: Sim.

DO3: Considero pouco valorizado, assim como o curso de agronomia em Conceição do Araguaia e o próprio Campus.

D04: Pelos alunos, sim.

D05: Não há valorização precisa por parte de muitos professores, mas pelos alunos sim. 
Os professores que responderam deixam a impressão de estarem pouco motivados. Portanto, sugere-se que as motivações dos professores sejam colocadas como diagnóstico negativo encontrado na pesquisa para futuros estudos e intervenções.

As dificuldades na estruturação do estágio de vivência foram questionadas e $80,00 \%$ dos pesquisados concordaram que existiam problemas neste quesito (Tabela 2), justificando suas respostas com os seguintes comentários:

D01: Deveria ter uma participação maior por parte dos docentes.

DO2: A experiência metodológica do estágio de vivência, criado pelo estudante é composta de três etapas, que não existem na proposta de estágio do IFPA, Campus Conceição do Araguaia. São estas: 1 - preparação das famílias e dos alunos, 2 - vivência (apenas essa etapa é seguida no IF) e 3 avaliação, composição de resultados e espaço de discussão. Minha sugestão é pela inclusão das duas etapas ausentes na metodologia do estágio de vivência do IFPA.

DO4: Deve haver maior acompanhamento técnico.

Avaliando o Projeto Pedagógico do Curso de Graduação em Engenharia Agronômica do IFPA, verificou-se que o docente 2 estava correto em suas colocações, pois as duas etapas às quais fez referência estão previstas, porém, não são usadas pelo fato de o curso ter se adaptado a realidade do aluno da região.

O projeto pedagógico e o estágio de vivência no momento em que se encontra em concordância são responsáveis por contribuir para a atuação dos alunos na veracidade social na qual estão inseridos, por intermédio de atividades reais. Une a teoria aprendida com a prática, abrangentes, como conhecimento do solo, a relação da plantação com o tempo, as "manhas" da natureza, entre outros. Despertando a capacidade dos mesmos de análise, compreensão e explicação de uma maneira individual, crítica e criativa.

Uma das funções do órgão social que denominamos escola é proporcionar um ambiente simplificado. Selecionando os aspectos mais fundamentais e que sejam capazes de despertar reações da parte dos jovens, estabelece a escola, em seguida, uma progressão, utilizando-se dos elementos adquiridos em primeiro lugar como meio de conduzi-los ao sentido e compreensão real das coisas mais complexas (Dewey, 1959, p. 21).

O foco, o objeto de estudo e o espaço onde acontece a metodologia do estágio são as centrais características que discernem a mesma, das demais disciplinas pedagógicas inseridas no currículo escolar brasileiro atualmente, sendo assim, a maior responsabilidade do lecionado em transmitir cautelosamente, o significado do trabalho agronômico, adaptado às novas necessidades populacionais e seus riscos financeiros e comprometimento com a saúde.

O próximo indicador dedicou-se, a saber, se o estágio de vivência estava sendo aplicado de forma correta. $80,00 \%$ dos entrevistados afirmaram que sim (Tabela 2), conforme se exemplifica nas falas seguintes:

HOLOS, Ano 36, v.4, e9641, 2020 
DO3: As dificuldades são normais e devem ser solucionadas.

DO4: Em minha opinião não existe forma correta e ou incorreta, mas sim propostas metodológicas diversas. No entanto, considero importante a inclusão de uma programação prévia e uma avaliação após as mesmas.

Como se viu na discussão acima, legalmente, há falhas, porém, há de se considerar que a escola adapta-se ao aluno, assim se faz necessário rever o currículo e atualizar o Projeto Pedagógico do Curso.

Os entrevistados foram questionados também se todos os professores deveriam participar do estágio de vivência, e 60,00\% responderam afirmativamente (Tabela 2). Dentre aqueles que concordaram, seguem-se algumas opiniões:

D01: Há muita falta de interesse, há um comodismo da maioria. Esquecem da importância de trabalharmos em conjunto. Nesse caso seria necessária uma intervenção por parte da direção de ensino para que todos participassem e criasse um cronograma de atividades para os 15 dias de estágio, no qual todos seriam incluídos.

DO5: Cada professor deve dar a assistência na sua área de atuação na Instituição, como obrigatoriedade.

A pouca participação dos professores no estágio de vivência é uma das justificativas do estudo, uma vez que os autores que respaldam a questão estagiária e embasam a descrição da pesquisa demonstram o quão importante é o estágio para o aluno.

São variáveis as trajetórias dantes percorridas pelos universitários. Alguns alunos portamse de maneira padrão ao de um estudante, concentrando-se apenas em cumprir adequadamente as exigências acadêmicas, enquanto outros, com maiores tendências e resolução profissional procuram mais ativamente desenvolver uma postura sempre voltada ao empreendedorismo de sua profissão, assim, consideram importante todas as etapas universitárias, apostando seu futuro profissional no aprendizado. É lógico, que a confiança no professor para os alunos do segundo caso é de vital importância (Lassance \& Gocks, 1995).

Deu-se ainda nesse grupo, uma investigação se a gestão geral do IFPA, Campus Conceição do Araguaia, contribui para uma boa execução do estágio de vivência, a qual revelou que $60,00 \%$ dos pesquisados achavam que sim (Tabela 2). Aqueles que opinaram negativamente justificaram: “[...] falta apenas exigir dos docentes que não querem participar. Pois o estágio de vivência tratase de um processo educacional" (Docentes que acompanharam os estagiários).

Já se percebe que o grupo de docentes estudados tem seus problemas respaldados na didática e metodologia da escola, que não estão atualizadas no Projeto Pedagógico do Curso de Graduação em Engenharia Agronômica do IFPA, Campus Conceição do Araguaia. 
Dando prosseguimento à pesquisa, agora referindo ao Grupo 3, onde 16 famílias de produtores participaram acolhendo os alunos no estágio de vigência, a pesquisa revelou quanto aos indicadores tamanho, característica e grau de escolaridade das famílias, que 50,00\% eram compostas por quatro pessoas, sendo que $81,25 \%$ eram de casais com filhos, e $18,75 \%$ possuíam em sua composição pessoas com escolaridade de nível médio a superior, tendo os demais partícipes apenas frequentado o ensino fundamental (Tabela 3).

Os produtores declararam quanto aos indicadores quem da família teve mais contato com o estagiário e qual o tipo de contato, que os mesmos tiveram contato com todos os membros das famílias $(100,00 \%)$, e enfatizaram que o tipo de contato foi profissional e muito afetivo, elencado por $62,50 \%$ do questionados (Tabela 3 ).

A avaliação de assiduidade dos alunos, registrada pelos produtores, demonstrou que 93,75\% dos estagiários permaneceram integralmente nas propriedades e desenvolveram as atividades propostas pelos produtores (Tabela 3 ).

O mesmo índice $93,75 \%$ foi registrado em respostas negativas quando do indicador houve incômodo para a família com a presença dos estagiários. Considerou-se assim, positiva a permanência dos alunos na propriedade (Tabela 3).

A pesquisa tem como parâmetro ideológico a fundamentação sob a importância do estágio de vivência para os produtores rurais, pois acredita-se que o contato com os estagiários traz benefícios para o estudante e o estudado. Sob a ótica desse grupo de famílias, 93,75\% declararam que o estágio de vivência é importante para os alunos, e $87,50 \%$ perceberam como benéfica a presença dos alunos em suas propriedades (Tabela 3).

O local estagiado e o favorecimento deste para o aprendizado foi alvo da discussão, uma vez que, importa à pesquisa melhorar os métodos que incentivem a vivência do estágio, para que este, junto com a teoria estudada, proporcione uma formação completa. Da universidade/instituição ao mercado de trabalho, apesar de parecer uma transição natural, há um longo caminho a percorrer, pois tudo depende do preparo prévio do estudante e o quanto este se empenhou para se formar como profissional (Bardagi et al., 2006).

O que se vê nessa transição é a incerteza da escolha profissional, podendo representar uma crise em relação à escolha profissional, uma vez que exige uma série de decisões quanto aos possíveis caminhos a se especializar (Bardagi et al., 2006).

Tabela 3: Indicadores disponibilizados em questionário às 16 famílias de produtores participantes da pesquisa, como parte da investigação sobre as relações estabelecidas entre a teoria e a prática no estágio de vivência, e sua contribuição para a formação acadêmica dos alunos.

\begin{tabular}{l|c|c}
\hline \multicolumn{1}{c|}{ Indicadores } & Número & Percentual (\%) \\
\hline Tamanho da família & & \\
Quatro pessoas & 5 & 50,00 \\
Três pessoas & 3 & 31,25 \\
Duas pessoas & & 18,75 \\
\hline Característica da família & \\
\hline \hline HOLOS, Ano 36, v.4, e9641, 2020 & 16
\end{tabular}




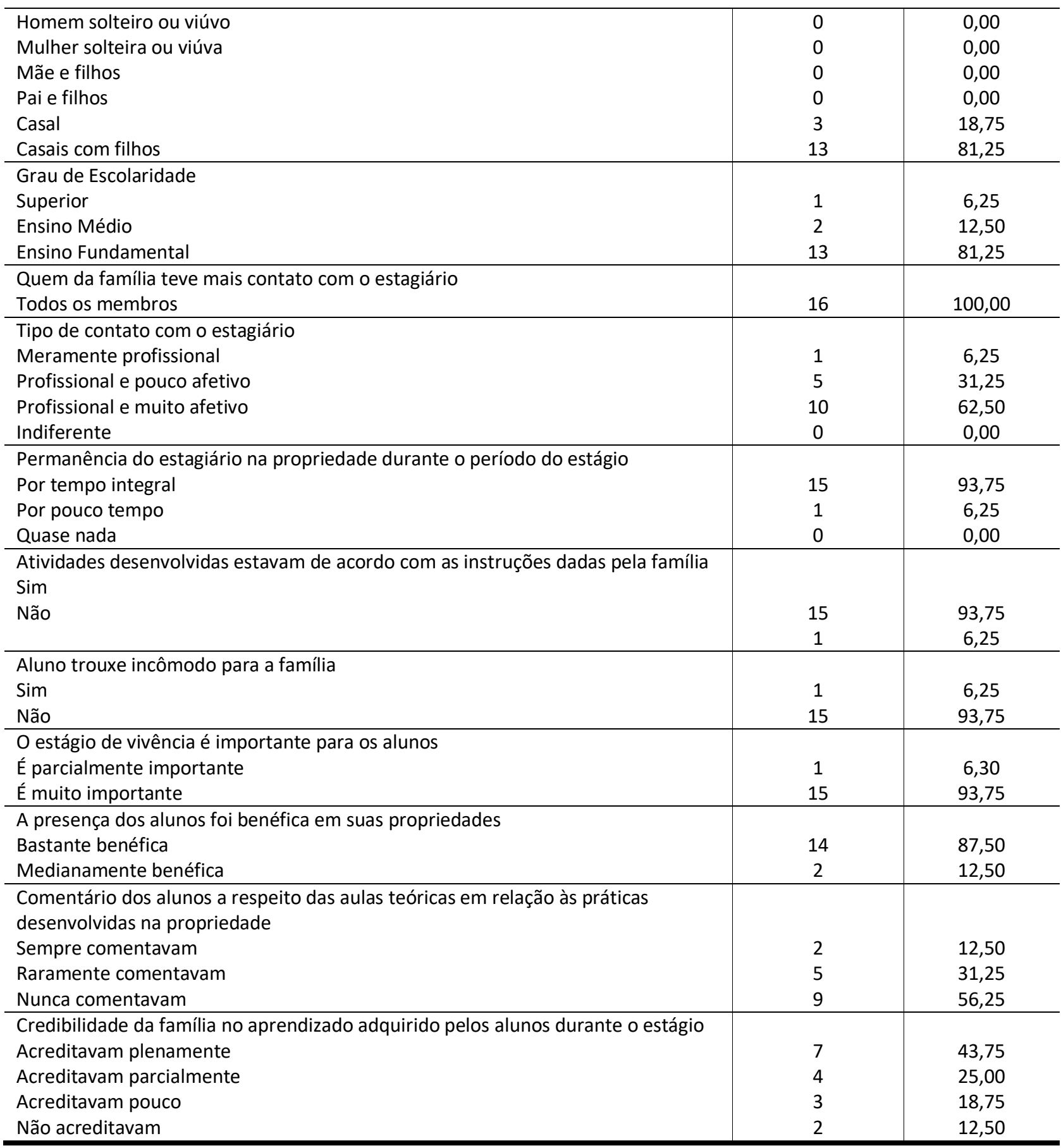

Portanto, o repasse do aprendizado dos alunos foi investigado, perguntando aos produtores se houve comentários sobre as disciplinas teóricas que tiveram em sala de aula, em relação à prática desenvolvida, e esses declararam que 56,25\% nunca fizeram comentários, 31,25\% comentaram às vezes, e $12,50 \%$ comentaram sempre com eles a teoria aprendida frente à prática (Tabela 3).

A credibilidade e confiança dos produtores no aprendizado, até então, adquirido pelos alunos estagiários é muito importante neste momento do estágio, e por isso foi questionada. Os produtores mostraram-se arredios, pois menos da metade $(43,75 \%)$ acreditavam plenamente no aprendizado dos alunos (Tabela 3).

HOLOS, Ano 36, v.4, e9641, 2020 
Analisando esse parecer, o que se observa, mesmo com todo o reconhecimento do trabalho de engenharia agronômica é que, ainda hoje há uma resistência dos produtores de pequeno a médio porte no que se refere a mudanças no processo de produção. Historicamente, ao longo da trajetória que envolve o homem o seu meio de produção agropecuário e seu contanto com a terra, registra-se um passado de lutas, que ainda prevalece, nas quais os produtores rurais sempre foram explorados por homens que da terra só conheciam os lucros.

Isso revela que a problemática do desenvolvimento da pequena propriedade vai além de fatores como "ignorância" ou "desinteresse". Na verdade, diz respeito a um tema pouco explorado pelos sociólogos rurais, que é a identidade do pequeno produtor. Portanto, ter um entendimento mais aprofundado dos fatores determinantes dessa resistência implica observar o processo de desenvolvimento rural a partir do impacto que este exerce na subjetividade desse pequeno produtor e de como tal subjetividade impacta esse processo. Como um dos componentes da complexa subjetividade do sujeito, a identidade possibilita a esse sujeito a sensação de continuidade no contexto social. É ela que lhe dá impressão de ser quem sempre foi, mesmo passando por várias mudanças durante sua história de vida. Além disso, a identidade está relacionada com a questão da diferença, pois é ela que particulariza os indivíduos, distinguindo-os no contexto social (Mendes \& Ichikawa, 2010, p. 5).

Assim, os autores citados, revelaram que a resistência à mudança e ao novo em pequenas propriedades é uma preocupação das políticas públicas. Na pesquisa, a maioria dos produtores acreditava plenamente que os estudantes possuíam conhecimento, mas este item não atinge $50,00 \%$ dos entrevistados, o que induz afirmar que eles demonstram receio quanto aos saberes dos estagiários.

Porém, há que se considerar a condição de estudante em curso, dos estagiários, que pode ser entendida pelos produtores como um quesito de incerteza ou aprendizado inacabado.

\section{CONSIDERAÇÕES FINAIS}

O estágio de vivência destaca-se como via fundamental pois possibilita aos alunos compreender a complexidade das práticas e das ações praticadas como alternativa no preparo para a inserção do profissional no mercado de trabalho.

Procurou-se descrever a importância do estágio de vivência focado na relação teoria e prática para a formação do aluno do Curso de Graduação em Engenharia Agronômica do IFPA, Campus Conceição do Araguaia, como meio de conhecer a realidade em que ocorre o estágio, a partir de uma visão dialética, como forma de superar a fragmentação entre teoria e prática, visando à formação da identidade profissional através da reflexão, do diálogo e da intervenção. A partir das discussões levantadas, percebeu-se a complexidade que envolve a prática nos cursos de Agronomia. Evidenciou-se que a relação dicotômica entre teoria e prática ainda está presente nos cursos e que muitas vezes, o estágio ainda é visto e tratado nos cursos como a parte prática em si do mesmo. 
A pesquisa observou um enorme desejo para romper com os moldes anteriores do estágio de vivência, onde nunca se coletava dados sobre o que acontecia, nem tampouco documentos que respeitassem o estágio desenvolvido pelo aluno; mas para que isso ocorra, entre outras condições, é necessário ampliar a reflexão entre os alunos, sobre o que eles têm vivenciado, e ampliar e incentivar a troca de experiência entre alunos e produtores que já tenham conhecimento e os que não têm.

Relatando sobre a questão da reflexão sobre o estágio, apesar das falhas que ainda existem, como a exemplo da falta de valor referente ao relatório pós-estágio, é importante ao aluno fazêlo, principalmente, porque este poderá levá-lo a refletir sobre sua formação, sua participação no contexto escolar e suas perspectivas enquanto futuro agrônomo. Mas é preciso que esse relatório seja lido e discutido em sala, para que, por meio das discussões, o aluno possa entender as dificuldades vivenciadas. Essas discussões podem ensinar ao aluno estagiário a como lidar com as dificuldades, especialmente quando em contato com as experiências de outros colegas. Refletir junto com os colegas e com o professor orientador do estágio pode suscitar a busca de soluções, ou pelo menos, de alternativas. Só escrevê-lo e entregar ao professor não terá efeito na formação desse aluno, tanto quanto se houver discussões e reflexões sobre as experiências vividas.

Vê-se também, a importância de todos tentarem contribuir mais com a escola, no sentido de dar algum retorno a ela, ou pelo menos, aos produtores/familiares que se dispõe a receber os estagiários. Os relatórios de estágio são ferramentas úteis para observar as experiências vivenciadas, mas vale salientar que seria interessante ter acesso a eles imediatamente quando os alunos retornassem, para se obter mais detalhes de todo o processo vivenciado, o que não é possível, visto ser entregue somente ao final da disciplina. Além disso, observa-se a necessidade de usar outros métodos que possam fornecer mais informações e esclarecimentos, uma vez que só os questionários não são capazes dessa realização.

Por fim, não se pode deixar de destacar como um ponto importante a ser pesquisado, as crenças que os alunos têm sobre o estágio e a forma como ele é desenvolvido, a fim de observar as implicações dessas crenças na vivência do mesmo. Os acadêmicos reconhecem e afirmam que no estágio de vivência se intensifica a relação teoria e prática, porém, não fica explicitado se isso se refere também aos aspectos de aprendizado ou se limita apenas à aplicação de um conhecimento específico como o ensino de um determinado conteúdo de Agronomia.

Embora o estágio de vivência tenha sido reconhecido pelos acadêmicos como um tempo de experiências intensas, não houve socialização efetiva entre os grupos participantes, nem com a coordenação/gestão, nem tampouco com a comunidade acadêmica. É preciso investigar continuamente a intenção real dos alunos para a sua formação. Nos relatórios, como já citado, há ausência de reflexões sobre a forma como acontece tal socialização dessa experiência, pois se verificou baixa qualidade descritiva, também havendo identificação de plágio, ou seja, estes são problemas que devem ser revistos, pois além de prejudicar a avaliação do "feedback" por parte 
dos alunos, deve propor uma reflexão de como melhorar o processo de avaliação e evitar que isto ocorra futuramente.

\section{REFERÊNCIAS}

Alexandre, J. W. C., \& Ferreira, J. J. A. (2001). Um estudo empírico da aplicação da GQT nas empresas manufatureiras de portes médio e grande do estado do Ceará. Produto \& Produção, 5(1), 33-47.

Bardagi, M., Lassance, M. C. P., Paradiso, A. C., \& Menezes, I. A. (2006). Escolha profissional e inserção no mercado de trabalho: Percepções de estudantes formandos. Psicologia Escolar $e$ Educacional, 10(1), 69-82.

Brasil. (2013). Resolução n. ${ }^{\circ}$ 466, de 12 de dezembro de 2012. Dispõe sobre as diretrizes e normas regulamentadoras de pesquisas envolvendo seres humanos. Diário Oficial da República Federativa do Brasil, Brasília.

Brito, L. C., Vasconcelos, J. C., Carvalho, C. A. S., Coelho, R. F. R., \& Benjamim, A. M. S. (2018). Relato de experiência de um estágio de vivência no município de Irituia Estado do Pará. Cadernos de Agroecologia, 13(1), 1-6.

Cardoso, A., Silva, M. B., Souza, J. V. S., Silva, J. C. C., Souza, L. S. G. S. L. (2009). Estágio interdisciplinar de vivência e a formação da consciência agroecológica. Revista Brasileira de Agroecologia, 4(2), 4505-4507.

Coutinho, P. W. R., Silva, J. N., Oliveira, L. M., Santos, C. S., \& Mota, A. V. (2013). Estágio de Vivência no projeto de Assentamento Benedito Alves Bandeira no município do Acará - PA. Cadernos de Agroecologia, 8(2), 1-4.

Cruz, J. B. (2007). Laboratórios. Brasília: Universidade de Brasília.

Dewey, J. (1959). Democracia e Educação. Introdução à filosofia da Educação (3a ed). São Paulo: Nacional.

Freire, P. (2002). Educação e atualidade brasileira. São Paulo: Cortez.

Freitas, A. F., Freitas, A. F., Silva, M. G., \& Pedra, M. S. (2011). A vivência da realidade agrária como instrumento de formação social e profissional. Vivências, 7(13), 53-61.

Google Earth. (2019). O globo terrestre mais detalhado do mundo. Recuperado em 28 outubro, 2019, de https://www.google.com.br/intl/pt-BR_ALL/earth/

Lassance, M. C. P., \& Gocks, A. (1995). A formação da identidade profissional em universitários: a questão da prática. In /l Simpósio Brasileiro de Orientação Vocacional e Ocupacional.

Likert, R. (1932). A technique for the measurement of attitudes. Archives of Psychology, 22(140), $1-55$. 
Little, P. E. (2003). Territórios sociais e povos tradicionais no Brasil: por uma antropologia da territorialidade. Anuário Antropológico, 28(1), 251-290.

Lopes, T. R., Freddo, A., Periotto, F., \& Pletsch, A. L. (2013). Utilização de recursos didáticos para o ensino de algas. In 64 Congresso Nacional de Botânica.

Mantoan, M. T. E. (2004). Por uma escola para todos. Campinas: Universidade Estadual de Campinas.

Mendes, L., \& Ichikawa, E. Y. (2010). O desenvolvimento tecnológico e o pequeno produtor rural: construção, desconstrução ou manutenção da sua identidade? Cadernos Ebape, 8(1), 167-183.

Monteiro, J. S., \& Silva, D. P. (2015). A influência da estrutura escolar no processo de ensinoaprendizagem: uma análise baseada nas experiências do estágio supervisionado em Geografia. Geografia Ensino \& Pesquisa, 19(3), 19-28.

Nicola, J. A., \& Paniz, C. M. (2016). A importância da utilização de diferentes recursos didáticos no ensino de biologia. InFor, 2(1), 355-381.

Paschoal, E. (2017). A importância do engenheiro agrônomo para a sociedade. Recuperado em 17 janeiro, 2017, de https://educacao.uol.com.br/colunas/engel/2009/03/06/a-importancia-doengenheiro-agronomo-para-a-sociedade.jhtm

Piletti, N. (1997). Psicologia Educacional. São Paulo: Ed. Ática.

PPC. (2011). Projeto Político Pedagógico do Curso de Agronomia. Conceição do Araguaia: Instituto Federal de Educação, Ciência e Tecnologia do Pará.

Tagcrowd. (2019). Create your own word cloud from any text to visualize word frequency. Recuperado em 25 dezembro, 2019, de https://tagcrowd.com/

Yin, R. (2014). Estudo de caso. Planejamento e métodos (5a ed). Porto Alegre: Bookman.

\section{COMO CITAR ESTE ARTIGO:}

Batista, G., Santos, G.A., Marino, T.B., Gregorio, S.R., Vita, G.F. (2020). Estágio de vivência em Engenharia Agronômica: relação entre o teórico e o prático. Holos, 36(4), 1-22.

\section{SOBRE OS AUTORES}

\section{GISELLE BATISTA}

Zootecnista; Mestre em Educação; Programa de Pós-Graduação em Educação Agrícola da Universidade Federal Rural do Rio de Janeiro (UFRRJ).E-mail: azebuadas@hotmail.com

ORCID ID: http://orcid.org/0000-0003-0104-3689

\section{GABRIEL ARAÚJO SANTOS}

Agrônomo; Mestre em Agronomia; Doutor em Química do Solo; Professor Titular da Universidade Federal Rural do Rio de Janeiro (UFRRJ); Pós-Graduação em Educação Agrícola da Universidade Federal Rural do Rio 
de Janeiro (UFRRJ).E-mail: gasantos@ufrri.br

ORCID ID: http://orcid.org/0000-0002-4054-1763

\section{TIAGO BADRE MARINO}

Bacharel em Ciência da Computação. Mestre em Engenharia de Transportes. Doutor em Informática. Professor Adjunto da UFRRJ. Programa de Pós-Graduação em Educação Agrícola. Universidade Federal Rural do Rio de Janeiro (UFRRJ). E-mail: tiagomarino@hotmail.com

ORCID ID: http://orcid.org/0000-0002-9045-3059

\section{SANDRA REGINA GREGORIO}

Nutricionista; Mestre em Ciência e Tecnologia de Alimentos; Doutor em Ciências de Alimentos; Professora Titular da Universidade Federal Rural do Rio de Janeiro (UFRRJ); Programa de Pós-Graduação em Educação Agrícola da Universidade Federal Rural do Rio de Janeiro (UFRRJ). E-mail: gregorio.sandra@gmail.com ORCID ID: http://orcid.org/0000-0001-9935-3479

\section{GILMAR FERREIRA VITA}

Biólogo; Gestor Ambiental; Mestre em Biologia Animal; Doutor em Biologia Animal; Pós-Doutorando em Educação; Programa de Pós-Graduação em Educação Agrícola da Universidade Federal Rural do Rio de Janeiro (UFRRJ). E-mail: gilmarferreiravita@yahoo.com.br

ORCID ID: http://orcid.org/0000-0001-9479-6414

Editor(a) Responsável: Francinaide de Lima Silva Nascimento

Pareceristas Ad Hoc: José Alves e Luiz Ferreira

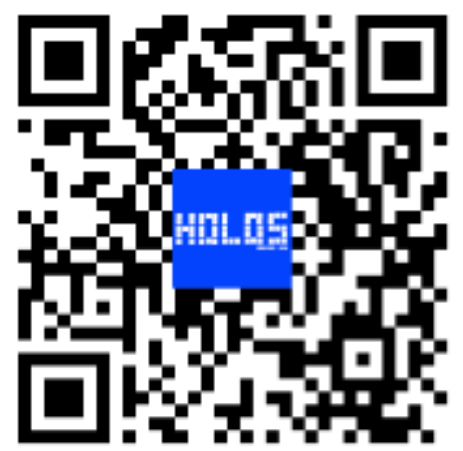

Recebido: 04 de abril de 2020

Aceito: $\mathbf{2 4}$ de junho de 2020

Publicado: 01 de julho de 2020 